\title{
Öğretmenlerin Dijital Vatandaşlığa Yönelik Algılarının İncelenmesi
}

\section{Serdar ARCAGÖK*}

Öz: $\mathrm{Bu}$ araştırmanın amacı öğretmenlerin dijital vatandaşlığa yönelik algılarını belirlemektir. Araştırmada betimsel tarama modeli kullanılmıştır. Araştırmanın evrenini 2018-2019 öğretim yılında Şırnak il merkezindeki eğitim kurumlarında farklı branşlarda görev yapan öğretmenler oluşturmaktadır. Araştırmanın örneklemini ise Şırnak il merkezindeki eğitim kurumlarında görev yapan ve seçkisiz yolla belirlenen 215 öğretmen oluşturmaktadır. Araştırma verileri, “Dijital Vatandaşlık Ölçeği” aracılığıyla sağlanmıştır. Elde edilen veriler SPSS paket programı ile analiz edilmiştir. Elde edilen bulguların analizi sonucunda verilerin normal dağılım gösterdiği saptandığından araştırmada bağımsız örneklem t testi ve tek yönlü Anova analizleri kullanılmıştır. Ayrıca aritmetik ortalama ve standart sapma değerleri kullanılmıştır. Araştırma sonucunda öğretmenlerin dijital vatandaşlık algılarının orta düzeyde olduğu belirlenmiştir. Öğretmenlerin dijital vatandaşlık algılarının branş değişkenine göre farklılaşmadığı saptanmıştır. Buna karşın erkek öğretmenlerin dijital vatandaşlığa yönelik algıları kadın öğretmenlere göre daha yüksek düzeyde belirlenmiştir. Ayrıca 1-5 yıllık mesleki kıdeme sahip öğretmenlerin dijital vatandaşlık algısı diğer mesleki kıdeme sahip öğretmenlere göre daha yüksek düzeyde tespit edilmiştir.

Anahtar Kelimeler: Alg1, Dijital vatandaşlık, Küreselleşme, Öğretmen

\section{Investigation on Teachers' Perceptions of Digital Citizenship}

Abstract: The main aim of this research is to determine teachers' perceptions of digital citizenship. In this research, cross-sectional survey model is used. The population of the research included teachers working in different discipline of Ministry of Education at Şırnak city in 2018-2019 academic year. The sample consisted of 215 teachers selected randomly. The validity and reliability of the data collection tool of the study were provided by means of the scale. The statistical analysis of the results obtained from this research was done using the SPSS

\footnotetext{
* Dr. Öğr. Ü. Çanakkale Onsekiz Mart Üniversitesi Eğitim Fakültesi, Temel Eğitim Bölümü. ORCID: orcid.org/0000-0002-4937-3268, E mail: serdar_arcagok21@comu.edu.tr.
} 
packet program. As the results of the analysis indicated that the data showed normal distribution. independent sample $t$ test and one-way ANOVA were used in the study. In addition, arithmetic mean and standard deviation values were used. Therefore, independent sample t test and one-way Anova statistical tests were used in the study. As a result of the research, it was determined that the teachers' perception of digital citizenship was middle level. On the other hand, perceptions of male teachers towards digital citizenship determined at a higher level than female teachers. In addition, the perception of digital citizenship of teachers with 1-5 years of professional seniority determined at a higher level than teachers with other professional seniority

Keywords: Digital citizenship, Globalization, Perception, Teacher.

\section{Giriş}

Geçmişte Teşkilât-1 Esasiye Kanunu olarak adlandırılan anayasa, devletin temelde kuruluş amacı ve örgütlenmesi ile beraber devlet içinde yaşayan bireylerin hak, özgürlük ve yükümlülüklerini düzenleyen, bildiren temel kanundur. 18. Yüzyılın sonlarına doğru önce ABD'de sonra da Fransa'da yazılı anayasalar şeklinde ortaya çıkmıştır. Anayasanın ortaya çıkmasının temel dayanağı ise devletin kuruluşunun temeli ile ilgili yazılı ve yazısız tüm kuralları dağınık görünümden kurtararak tek metin halinde uyarlamak, uyumlu ve tutarlı bir bütünlük ortaya çıkartmaktır. Bu eğilim, temelini akılcılık (rasyonalizm) yaklaşımından almıştır. Küreselleşen dünyamızda ise anayasa denilince akla bu denli geniş bir tanımlamadan çok sadece yazılı bir temel kanun akla gelmektedir (Doğan, 2005).

Anayasa bireylerin hak, özgürlük ve yükümlülüklerini bildiren yazılı kanunlardır. Bu kanunlara uyan bireylere de anayasaya göre 'vatandaş' denmektedir. Bu çerçevede vatandaşlik bir devlet veya millet tarafindan bireye atfedilen yasal bir statüdür (Engle ve Ochoa, 1988, Akt; Merey, Karatekin ve Kuş, 2012). Vatandaş benimsenmiş, onaylanmış değer ve ilkeleri ihlal etmeyen, belirli bir inanç ve değerlere sahip, ulusal ve evrensel kabul edilen değerlere sayg1 gösteren, bunları uygulayan bireyler şeklinde tanımlanmaktadır. Bunlar göz önünde bulundurulduğunda birey, bir vatandaş olarak kendisinden istenen ve beklenen görevleri bilen aynı zamanda bunları uygulayan kişidir (Barth \& Demirtaş, 1997). Kan (2009) ise ülkelerin vatandaşlık kavramını, başlangıçta var olan görev ve yükümlülüklere uygun davranan, sorumluluk yetisine sahip vatandaş yetiştirmek şeklinde ifade etmiştir. 
Dünya çapında yaşanan teknolojik gelişmeler, küreselleşme bir diğer adıyla dijitalleşme diye bir kavramı ortaya çıkarmıştır. Dijitalleşme, ortaya çıktığında ekonomik ve ticari işlerde kullanılan bir kavramken bugün sosyal medyanın ve internet ortamındaki sosyal alanların da oluşmasıyla kavram içeriği zenginleşmeye, çeşitlenmeye başlamıştır (Tezcan, 2004).

Teknolojik aletler ve internet, gelişen teknolojinin başlıca unsurları olarak görülürken mobil uygulamalar ve sosyal medya bu unsurların yarattığı değişimler olarak değerlendirilebilir. Değişimler ortaya çıktıkça ihtiyaç duyulan hemen hemen her şey elektronik ortamlardan temin edilmeye başlanmıştır. Bunların başında e- ticaret, e-devlet, e-kitap, e-nabız gibi resmi evrakların sanala dökülmüş hali ortaya çıkmaktadır. Eğitimden sağlığa alışveriş, ticaret gibi birçok sektörde erişim kolaylığı ortaya çıkmıştır. Bu dijitalleşme süreci de 'dijital vatandaşlık’ gibi bir kimlik kavramı ortaya çıkarmıştır. İnternet aracılığıyla vatandaşlık kavramı zenginleşip genişlemeye başlayarak ulusların sınırlarını topraktan çok kablolar belirlemeye başlamıştır. Bu noktadan hareketle dünyanın herhangi bir noktasında yaşanan bir olay diğer kesimde yaşayan bireyler tarafından çok kısa bir sürede bilinmekte ve ortak bir eylem aynı anda her kesimde gerçekleşmektedir. Bireyler istedikleri her an her bilgiye Google vb. arama motorlarıyla kolaylıkla erişim sağlamaktadır. Tüm mobil araçlar vasıtası ile sosyal medya kullanılarak evrendeki politik, siyasi, ekonomik olaylara bireyler tarafindan anında ulaşılmaktadır (Engin \& Sarsar, 2015)

Bilgi iletişim teknolojileri ortak bir dünya düzeni ve evrensel kültürün oluşmasına katk1 sağlamıştır. Dünyanın bir ucundaki olaylardan dijital dünya aracılığıyla haberdar olunmakla birlikte bunlara karşı bireyler aynı ortamda duygu ve düşüncelerini sergilemektedirler. Dijital ortamlarda gerçekleşen eylemler dikkate alındığında vatandaşların sadece yaşadığı topluma değil tüm evrene karşı sorumlulukları olduğunun bilincinde olması beklenmektedir. $\mathrm{Bu}$ çerçevede evrene karşı kendisini sorumlu hisseden, evrensel bilinç ve duyarlılığa sahip vatandaşların yetiştirilmesi beklenmektedir. Söz konusu ölçütlere sahip olan vatandaş “dijital vatandaş" şeklinde adlandırılmaktadır (Farmer, 2010; Kan, 2009). "Dijital vatandaş" hem kendi ülkesinin hem de yaşadığ 1 ve sorumluluğunu üstlendiği dünyanın vatandaşıdır. Bu bağlamda "dijital vatandaş" dünyada yaşanan her türlü olay ve gelişmelere bireysel ve evrensel açıdan yaklaşan, gelecek kuşaklar için daha yaşanabilir bir ortam bırakmak için uğraşan evrensel bir kişilik olarak belirtilmektir. 
Çubukçu ve Bayzan (2013)'a göre ise 'dijital vatandaş'; kendinde olan bilgi ve iletişim olanaklarını kullanırken eleştirebilen, sanal ortamda yapılan davranışların etik sonuçlarının farkında olan, teknolojiyi başkalarına zarar vermeyecek şekilde kullanabilen, internet ortamında iletişim hakkını kullanan, yaptığı paylaşımlarında ve işbirliğinde doğru tutumu sergileyen ve başkalarını da buna yönelten bireydir. Çubukçu ve Bayzan (2013), aynı zamanda dijital vatandaşlığı, en genel kapsamı itibariyle teknoloji kullanımına ilişkin hak ve sorumluluklar bütününde yer alan davranış normları olarak ifade etmektedir.

Dijital vatandaş özetle teknolojiyi kullanırken gösterdiği tutum ve davranışların sorumluluğunu alabilme becerisi olarak tanımlanabilir (Mossberger, Tolbert \& McNeal, 2007).

Oxfam (2006)'a göre bireyi dijital vatandaş olarak tanımlayabilmek için aşağıdaki ölçütlere sahip olması beklenmektedir. Bu çerçevede dijital vatandaşlığa yönelik ölçütler şu şekilde sıralanabilir:

- $\quad$ Evrenin ve evrensel bir vatandaşlik boyutunun bilincinde ve yükümlülügünde olmak,

- $\quad$ Her türlü çeşitliliğe saygılı ve hoşgörülü olmak,

- $\quad$ Gelişen dünyanın farkında olarak bu dünyayı yakından izlemek,

- $\quad$ Sosyal devlet bilincini savunmak, adaletsizliğe karşı olmak,

- $\quad$ İçinde yaşadığı veya farklı kıtalarda oluşmuş her türlü çok kültürlü topluluklara katılım sağlamak,

- $\quad$ Kişisel çıkardan çok, toplum çıkarını gözetmek, adalet için her türlü eylemi desteklemek,

- Yaptığı ve yapacağı her türlü eylemlerin sonuçlarının sorumluluğunu üstlenmektir.

Eğitimin asıl amacı ülkesine ve dünyaya fayda sağlayan, üretken bireyler yetiştirmektir. Hedeflenen şekilde vatandaş yetiştirme eğitim alanında ağırlıklı olarak sosyal bilgiler dersi öğretim programı kapsamında verilmektedir. Dünya'nın küreselleşmesi ile bireyler günümüzde yalnızca bir ülkenin sınırları içinde kalmaz. Aksine küreselleştikçe ortaya evrensel bir kültür ortaya çıkmakta ve bireylerin ortak bir paydada buluşma zorunluluğu doğmaktadır. Bunlar değerlendirildiğinde ise daha bilinçli, sorumluluk sahibi bireyler yetiştirmek için 'dijital vatandaşlık' eğitimlerine yer verilmeli, dünyada yaşanan olaylara karşı duyarlı vatandaşlar yetiştirilmesi hedeflenmelidir (Stavenhagen, 2008). 
Dünyanın dijitalleşmesi vatandaşlık kavramının da irdelenmesini gerektirmiştir. Bireylere verilen vatandaşlık derslerinin içeriklerinin (dinsel, etnik, teknolojik, kültürel ) gelişip yaygınlaşması eğitimde de değişimler yapılmasına neden olmuştur. Çünkü eğitimcilerin çağı yakalamak, çağın gerisinde bireyler yetiştirmemek için vatandaşlık eğitiminin içeriğinin yeniden yapılandırmaları, zenginleştirmeleri ve bir program yardımıyla geliştirmeleri gerekmektedir. Aksi takdirde çağın getirdiği sorunlarla baş edemeyen, evrensel kültürden yoksun ve dünyada meydana gelen olaylara duyarsı, salt kendini düşünen ve dijital platformlarda yapmış olduğu eylemlerin yükümlülüklerini bilmeyen bireylerin yetişecektir (Kaya \& Kaya, 2012).

Dijital vatandaşlık ve vatandaşlık kavramlarının birbiriyle çatıştığı söylemleri doğru olmamakla birlikte bu kavramlar iç içe geçmiş bir uyum halindedir. Sürekli gelişen ve yenilenen dünyada bireylerden sadece içinde yaşadığı milletin hak ve ödevlerinin gereklerini beklememeli onlara tüm dünya toplumlarının etnik, kültürel, dilsel, dinsel ve teknolojik açıdan farklı olan yapılarını tanıyıp öğrenmelerine olanak sağlanmalıdır (Banks, 2004).

Gelecek nesilleri yetiştirmek amacıyla hazırlanacak olan vatandaşlık eğitimi gençlerin kendi kültürlerinin yanı sıra dünya kültürlerini kavramaya, etkileşimde bulunmaya ve de uçsuz bucaksız evrenin gerektirdiklerini algılamalarına imkân sağlamalıdır (Ortloff, 2011).

Son dönemlerde özellikle İngiltere ve ABD'deki birçok eğitim kurumunda dijital vatandaşlık hakkında programlar ve stratejiler kullanılmaya geliştirilmeye başlanmıştır. Oxfam tarafından İngiltere'de ortaya çıkan dijital vatandaşlık programı zamanla Galler, İskoçya ve Kuzey İrlanda'yı da etkisi altına alarak küresel bir şekilde etkili olmaya başlamıştır. Programların içeriğinde dijital vatandaşlık; dil edinimi, kültürler arası sorumluluk, çevresel farkındalık, medya okuryazarlığı, dünya tarihi ve literatürü gibi konular derinlemesine incelenmektedir. İngiltere dijital vatandaşlık eğitimi konusunda başat rol oynamaktadır. İngiltere' de gerçekleşen bu eğitimde özellikle insan hakları, dünyadaki ülkeler, kıtalar, kültürler arası evrensel bir dayanışmayı sağlama ve evrensel bir sorun olan fakirliği azaltma gibi konulara dikkat çekilmektedir (Schattle, 2008).

Oxfam tarafından geliştirilen dijital vatandaşlık eğitim programının temel hedefi gençleri uluslararası bir bağlılık ve duyarlılıkla yetiştirip onlardan bir dünya vatandaşı ortaya çıkarmaktır (Banks, 2004). Milliyetçi görüşlere göre dünya vatandaşı olmak diğer bir deyişle dijital vatandaşlık; egemenlik kaybı, ülke çıkarlarını göz ardı etme gibi algılansa da aslında 
dijital vatandaşlığın amacı farklı kültürlere saygı duyan evrensel konular için endişelenen yurttaş yetiştirmektir (Gibson, Rimmington \& Landwehr-Brown, 2008 ).

Uluslararası oluşturulmuş kurum ve kuruluşlar evrensel barış ve iş birliğine hizmet etmek amacıyla kurulmuştur. $\mathrm{Bu}$ hizmetlerden faydalanan birçok dünya vatandaşı bulunmaktadır. Batı ülkelerindeki bazı eğitim bakanlıkları ülke sınırları dışında gerçekleşen organizasyonlar planlamış ve pek çok özel şirket evrensel vatandaş yetiştirmek için ortak bir görüş, program tasarlama çabasında bulunmuştur. Fakat bu anlayışa engel olan temel etken okul-kapasite ve eğitimdeki güdülenme eksikliğidir. Söz konusu eksiklikler dijital vatandaşlık eğitimini olumsuz yönde etkileyebilmektedir. Bunun giderilmesi ancak okullarda nitelikli öğretmenler aracılığıyla sağlanabilir. Bu bağlamda 'Dijital vatandaşlık' kimliğinin beklenen hedefte bireylere kazandırılması büyük oranda eğitimle mümkündür (Zahabioun, Yousefy, Yarmohammadian \& Keshtiaray, 2013).

Tüm dünyayı ilgilendiren evrensel problemler ( kültürel, sosyoekonomik, politik ve çevresel) öğretmenleri, öğrencilerini bu problemlere duyarlı, farklı kültürlere saygı duyan, empati kurabilen ve evrensel problemleri çözmek için cesaret gösterebilen, modern dünyaya ayak uydurabilen öğrenciler yetiştirmeye yöneltmiştir. Dijital dünyanın gereklerinin farkında olan, üzerine düşen sorumluluğu yerine getirebilen bireyleri yetiştirmek için eğitimcilere, alanında uzman program geliştiricilere ve araştırmacılara büyük sorumluluk düşmektedir. Modern zamanlarda eğitimde eşitliği sağlayabilmek için öncelikle dünyadaki diğer bireylerle yarışabilecek yeterli donanımlara ve becerilere sahip olmakla mümkündür. Bunun için öğrencilere dönemin şartlarına uygun eğitim, mesleki donanım, ana dili dışında en az bir yabancı dil ve entelektüellik gibi onu sıradan bir birey olmaktan farklı kılacak yetenekler kazandırılmalıdır. Bu yeteneklerin kazandırılmasında dijital vatandaşlık eğitimi büyük önem taşımaktadır (Lim, 2008; Takkac \& Akdemir, 2012).

İlgili alanyazın incelendiğinde dijital vatandaşlığa yönelik araştırmaların ağırlıklı olarak öğretmen adaylarıyla gerçekleştirildiği saptanmıştır (Aladağ ve Çiftçi, 2017; Aslan, 2016; Bakır, 2016; Bardakçı vd., 2018; Dere \& Yavuzay, 2019; Görmez, 2016; Kozan, 2018; Kocadağ, 2012; Sakallı, 2015; Som-Vural \& Kurt, 2018). Bununla birlikte dijital vatandaşlık kavramını sosyal bilgiler dersi bağlamında ele alan çalışmalara da rastlanmıştır (Aydemir, 2019; Karaduman, 2011; Turan, Karasu, 2018). Buna karşın öğretmenlerin dijital vatandaşlık kavramına yönelik görüşlerini irdeleyen araştırmaların sınırlı olduğu gözlemlenmiştir (Kilci, 
2019; Tatlı, 2018). Bilgi iletişim çağının zaman ve mekân açısından yakınsadığı çağımızda bilişim teknolojilerinin gelişmesine paralel olarak küreselleşen dünyada dijitalleşme kaçınılmazdır. Bu bağlamda dijitalleşen dünyada okul öncesinden lisansüstü öğretime kadar geçen sürede öğrencilerin farklı yetilerini geliştirme sorumluluğunu üstlenen ve çağın ihtiyaçlarına uygun nesiller yetiştirilmesinde önemli bir noktada olan eğitimcilere büyük sorumluluklar düşmektedir. Güncelliğini gittikçe artan bir oranda koruyan ve bireysel yaşamın vazgeçilmez bir olgusu haline dönüşen dijital vatandaşlık kavramının öğretmenlerin bakış açılarına göre betimlenmesinin alanyazına katkıda bulunacağı düşünülmektedir.

\section{Araştırmanın Amacı}

$\mathrm{Bu}$ araştırmanın amacı öğretmenlerin dijital vatandaşlığa yönelik algılarını belirlemektir. Bu çerçevede aşağıdaki araştırma sorularına yanıt aranmıştır.

1. Öğretmenlerin dijital vatandaşlık algıları hangi düzeydedir?

2. Öğretmenlerin dijital vatandaşlık algıları;
a. cinsiyete,
b. branşa,
c. mesleki kıdem değişkenlerine göre anlamlı farklılık göstermekte midir?

\section{Yöntem}

\section{Araştırma Modeli}

Araştırmada betimsel tarama modeli kullanılmıştır. Tarama modeli geçmişte ya da mevcut var olan bir durumu olduğu biçimde betimlemeyi amaçlayan bir modeldir (Karasar, 2000). Bu araştırmada öğretmenlerin dijital vatandaşlığa yönelik algıları var olduğu şekliyle betimlenmeye çalışıldığından bu model benimsenmiştir.

\section{Evren Örneklem}

Araştırmanın çalışma evrenini, 2018-2019 öğretim yılında Şırnak il merkezinde farklı branşlarda görev yapan 400 öğretmen oluşturmaktadır. Araştırmanın örneklemini ise basit seçkisiz (yansız) atama yoluyla belirlenen 215 öğretmen oluşturmuştur. Bu örneklem türünde evrendeki tüm birimler örneğe seçilmek için eşit ve bağımsız bir şansa sahiptir (Büyüköztürk vd., 2008). Bu araştırmanın birinci adımında evreni oluşturan branş öğretmenlerinin görev yaptığı okulların listesi belirlenmiştir. İkinci aşamada ise belirlenen okulların tümüne gidilerek seçkisiz yolla kararlaştırılan öğretmenlere ölçme aracı uygulanmıştır. Araştırma için gerekli 
örneklem büyüklüğü $n=N . t^{2}$ p.q/ $d^{2}$. (N-1)+t².p.q formülüyle hesaplandı ğında (Baş, 2003), 195 öğretmenin yeterli olduğu saptanmıştır. Bu çerçevede araştırmanın örneklemini oluşturan 215 öğretmen evreni karşılayacak düzeydedir. Araştırma örneklemine yönelik bilgiler Tablo 1 de gösterilmiştir.

Tablo 1. Çalışma Örneklemine İlişkin Betimsel Veriler

\begin{tabular}{lcc}
\hline Branş & $\mathrm{n}$ & $\%$ \\
\hline Sinıf Öğr. & 133 & 61.8 \\
\hline Diğer & 52 & 24.2 \\
\hline Okul Öncesi Öğr. & 30 & 14 \\
\hline Toplam & 215 & 100 \\
\hline
\end{tabular}

Tablo 1 dikkate alındığında 133 öğretmenin (\% 61.8) sınıf öğretmeni, 30 öğretmenin (\% 14) okul öncesi öğretmeni ve 52 öğretmenin ise (\%24.2) diğer branşlarda görev yapan öğretmenlerden oluştuğu görülmektedir.

\section{Veri Toplama Aracı}

Araştırmada Kuş vd., 2017 tarafından geliştirilen 'Dijital Vatandaşlık' ölçeği kullanılmıştır. Araştırmada kullanılan ölçek beş dereceli likert tipi bir ölçek olup sekiz faktör ve 49 maddeden oluşmaktadır. Faktörlerde yer alan maddelerin her biri; kesinlikle katıliyorum (5), katılıyorum (4), orta derecede katılıyorum (3), katılmıyorum (2) ve kesinlikle katılmıyorum (1) şeklinde derecelendirilmiştir. Ölçeğin genelinden alınabilecek en düşük puan 49, en yüksek puan ise 245 'dir. En düşük puan, dijital vatandaşlığın gerektirmiş olduğu bilgi ve becerilerin azaldığını en yüksek puan ise dijital vatandaşlığın gerektirmiş olduğu bilgi ve becerileri düzeyinin arttığını işaret etmektedir. Bununla birlikte ölçek beşli likert tipi bir yapıya sahip olup ölçekte aritmetik ortalamaya $(\bar{X})$ göre hesaplanmış puan aralıkları ise 1-1.80 "Kesinlikle Katılmiyorum”, 1.81-2.60 “ Katılmıyorum”, 2.61-3.40 “ Orta Derecede Kat1liyorum”, 3.414.20 "Katılıyorum” ve “ 4.21-5 “Kesinlikle Katılıyorum” şeklindedir. Ölçeğin geçerliği üç farklı yöntemle incelenmiştir. Bunlar; (1) faktör analizi, (2) madde toplam korelasyonları ve (3) madde ayırt edicilik özelliğidir. Açımlayıcı faktör analizi sonucunda 49 maddelik ölçeğin 8 faktörden oluştuğu tespit edilmiştir. Bu faktörlerin 1- İletişim (6 madde), 2- Hak ve sorumluluk (9 madde) ve 3- Eleştirel düşünme (7 madde) 4- Katılım (5 madde) 5- Güvenlik (6 madde) 6Dijital beceriler (5 madde) 7- Etik (4 madde), 8- Ticaret (7 madde) ile ilişkili olduğu belirlenmiştir. Ölçeğin madde yükleri ve varyansı açıklama oranları açısından geçerli bir ölçek olduğu tespit edilmiştir. Ölçeğin iç tutarlığı için Cronbach Alpha güvenirlik katsayıları 
incelenmiştir. Her bir faktöre ilişskin güvenilirlik katsayının 0.733 ile 0,829 arasında değişen değerler arasında olduğu tespit edilmiştir (Kuş vd., 2017). Elde edilen değerler çerçevesinde ölçeğin güvenilir ölçümler yapabildiği görülmüştür. Bu çalışmada her bir faktöre yönelik Cronbach Alpha güvenirlik katsayısı 0.72 ile 0.79 arasında belirlenmiştir.

\section{Veri Analizi}

Araştırmada nicel veri analiz programlarından SPSS paket programı kullanılmıştır. Araştırmada standart sapma (Ss) ve aritmetik ortalama $(\bar{X})$ değerleri kullanılmıştır. Bu değerler araştırma verilerinin betimlenmesi amacıyla kullanılmıştır. Bununla birlikte araştırma verilerinin normal dağılım gösterip göstermediği çarpıklık ve basıklık değerleri incelenerek hesaplanmıştır. Bu araştırmadan elde edilen çarpıklık ve basıklık değerleri (Skewness: 0.2, Kurtosis: 0.1) normal dağılım gösterdiğinden (George ve Mallery, 2010) verilerin analizinde bağımsız örneklem t testi ve tek yönlü Anova analizleri gerçekleştirilmiştir.

\section{Bulgular}

\section{Birinci Alt Probleme İlişkin Bulgular}

Öğretmenlerin dijital vatandaşlığa yönelik algı düzeyi 8 alt boyutta incelenmiş olup, bu boyutlara ilişkin aritmetik ortalama $(\bar{X})$ ve standart sapma değerleri (Ss) Tablo 2 de verilmiştir.

Tablo 2. Öğretmenlerin Dijital Vatandaşlık Kavramına Yönelik Algıılarına İlişkin Analiz Sonuçları

\begin{tabular}{lcc}
\hline Boyutlar & $\overline{\boldsymbol{X}}$ & Ss \\
\hline Dijital İletişim & 1.96 & .75 \\
Dijital Hak ve Sorumluluklar & 3.67 & .53 \\
Eleştirel Düşünme & 2.51 & .62 \\
Dijital Katılım & 3.38 & .86 \\
Dijital Güvenlik & 2.27 & .70 \\
Dijital Beceriler & 3.91 & 79 \\
Etik & 2.64 & .48 \\
Dijital Ticaret & 3.93 & .75 \\
Toplam & 3.11 & .32 \\
\hline
\end{tabular}

Tablo 2' ye göre ölçeğin bütününe bakıldığında öğretmenlerin dijital vatandaşlığa yönelik algılarının “ Orta derecede katılıyorum” ( $\bar{x}=3$. 11) şeklinde olduğu görülmektedir. Etik boyutta da öğretmenlerin benzer şekilde “ Orta derecede katılıyorum” ( $\bar{X}=2.64)$ şeklinde yanıt verdikleri belirlenmiştir. Öğretmenler dijital iletişim boyutuna “ Katılmıyorum” ( $\bar{x}=$ 1.96) Şeklinde yanıt vermiştir. Öğretmenlerin, eleştirel düşünme boyuna "Katılmıyorum" ( $\bar{x}=$ 2.51), benzer şekilde dijital güvenlik boyutuna da "Katılmıyorum" $(\bar{X}=2.27)$ şeklinde yanıt 
verdikleri belirlenmiştir. Öğretmenler dijital hak ve sorumluluklar "Katılıyorum" ( $\bar{X}=3.67)$, dijital katılım "Katılıyorum" ( $\bar{X}=3.38)$, dijital ticaret "Katılıyorum" $(\bar{X}=3.93)$ ve dijital beceriler boyutlarına "Katılıyorum” ( $\bar{X}=3.91)$ şeklinde yanıt verdikleri tespit edilmiştir.

\section{İkinci Alt Probleme İlişkin Bulgular}

Öğretmenlerin dijital vatandaşlığa yönelik algılarını oluşturan boyutların cinsiyet değişkenine göre farklılaşıp farklılaşmadığını belirlemek amacıyla bağımsız gruplar $\mathrm{t}$ testi uygulanmış ve sonuçlar Tablo 3'de gösterilmiştir.

Tablo 3. Öğretmenlerin Dijital Vatandaşlık Algı Düzeylerinin Cinsiyet Değişkenine Göre Analiz Sonuçları

\begin{tabular}{|c|c|c|c|c|c|c|c|}
\hline Boyutlar & Cinsiyet & $\mathbf{N}$ & $\mathbf{X}$ & Ss & Sd & $\mathbf{t}$ & $\mathbf{p}$ \\
\hline Dijital İletişim & $\begin{array}{l}\text { Kadın } \\
\text { Erkek }\end{array}$ & $\begin{array}{l}143 \\
72\end{array}$ & $\begin{array}{l}2.78 \\
2.23\end{array}$ & $\begin{array}{l}.58 \\
.82\end{array}$ & 203 & -4.54 & .00 \\
\hline Dijital Hak ve & Kadın & 143 & 3,63 & .56 & 203 & -1.24 & .21 \\
\hline Sorumluluklar & Erkek & 72 & 3.73 & .49 & & & \\
\hline Eleştirel & Kadın & 143 & 2.47 & .59 & 203 & -1.21 & .22 \\
\hline Düşünme & Erkek & 72 & 2.59 & .73 & & & \\
\hline \multirow[t]{2}{*}{ Dijital Katılım } & Kadın & 143 & 3.34 & .86 & 203 & -.80 & .42 \\
\hline & Erkek & 72 & 3.45 & .89 & & & \\
\hline \multirow[t]{2}{*}{ Dijital Güvenlik } & Kadın & 143 & 2.14 & .62 & 203 & -3.67 & .00 \\
\hline & Erkek & 72 & 2.53 & .79 & & & \\
\hline \multirow[t]{2}{*}{ Dijital Beceriler } & Kadın & 143 & .89 & .73 & 203 & -.30 & .76 \\
\hline & Erkek & 72 & 3.93 & .91 & & & \\
\hline \multirow[t]{2}{*}{ Etik } & Kadın & 143 & 2.63 & .44 & 203 & -.46 & .63 \\
\hline & Erkek & 72 & 2.67 & .55 & & & \\
\hline \multirow[t]{2}{*}{ Dijital Ticaret } & Kadın & 143 & 4.09 & .52 & 203 & -3.99 & .00 \\
\hline & Erkek & 72 & 3.63 & 1,00 & & & \\
\hline \multirow[t]{2}{*}{ Toplam } & Kadın & 143 & 3.05 & .27 & 203 & -2.48 & .02 \\
\hline & Erkek & 72 & 3.19 & .39 & & & \\
\hline
\end{tabular}

Tablo 3 de görüldüğü gibi öğretmenlerin dijital vatandaşlığa ilişkin algıları ölçeğin bütünü dikkate alındığında cinsiyet değişkeni açısından erkek öğretmenler lehine anlamlı bir fark göstermektedir $\left(\mathrm{t}_{(203)}=-2.48, \mathrm{p}<.05\right)$. Başka bir ifadeyle erkek öğretmenlerin dijital vatandaşlığa yönelik algıları $(\bar{X}=3$. 19) kadın öğretmenlere göre $(\bar{X}=3.05)$ daha yüksek düzeydedir. Cinsiyet değişkeni açısından anlamlı fark gösteren diğer boyutlardan biri ise dijital ticaret $\left(\mathrm{t}_{(203)}=-3.99 \mathrm{p}<.05\right)$ boyutudur. Bu boyutta kadın öğretmenlerin algıları $(\bar{x}=4.09)$ erkek öğretmenlerden $(\bar{X}=3.63)$ daha yüksek düzeydedir. Dijital güvenlik boyutunda $\left(\mathrm{t}_{(203)}=\right.$ $-3,67 ; \mathrm{p}<.05)$ ise erkek öğretmenlerin algıları $(\bar{X}=2.53)$ kadın öğretmenlere $(\bar{X}=2.14)$ göre daha yüksek düzeydedir. Dijital iletişim boyutu dikkate alındığında $\left(\mathrm{t}_{(203)}=-4,54 ; \mathrm{p}<\right.$ $.05)$ ise kadın öğretmenlerin algılarının $(\bar{x}=2.78)$ erkek öğretmenlere göre $(\bar{x}=2.23)$ göre 
daha yüksek düzeyde olduğu tespit edilmiştir. Öğretmenlerin dijital vatandaşlığa ilişkin algıları ölçeğin dijital hak ve sorumluluklar boyutunda cinsiyet değişkeni açısından anlamlı bir fark göstermemektedir $\left(\mathrm{t}_{(203)}=-1.24 \mathrm{p}>.05\right)$. Başka bir ifadeyle erkek öğretmenlerin dijital hak ve sorumluluklara yönelik algıları $(\bar{x}=3.73)$ kadın öğretmenlere göre $(\bar{x}=3.63)$ daha yüksek düzeyde olmasına rağmen aralarındaki fark anlamlı değildir. Eleştirel düşünme boyutunda ( $\left.\mathrm{t}_{(203)}=-1,21 ; \mathrm{p}>.05\right)$ ise erkek öğretmenlerin algıları $(\bar{X}=2.59)$ kadın öğretmenlere göre $(\bar{X}$ $=2.47$ ) daha yüksek düzeyde olmasına rağmen aralarındaki fark anlamlı değildir. Dijital katılım boyutunda $\left(\mathrm{t}_{(203)}=-1.24 \mathrm{p}>.05\right)$ ise erkek öğretmenlerin $(\bar{X}=3,45)$ kadın öğretmenlere göre $(\bar{X}=3, .34)$ algıları daha yüksek düzeydedir. Etik boyut da $\left(\mathrm{t}_{(203)}=-.46 \mathrm{p}>.05\right)$ cinsiyet değişkeni etkili bir değişken olmamasına rağmen erkek öğretmenlerin algıları $(\bar{X}=2.67)$ kadın öğretmenlere göre $(\bar{X}=2.63)$ daha yüksek düzeydedir. Ancak bu fark anlamlı değildir.

Branş değişkeni açısından öğretmenlerin dijital vatandaşlığa yönelik algı düzeyini oluşturan boyutların farklılaşıp farklılaşmadığını belirlemek amacıyla Tek yönlü anova testi uygulanmıştır. Uygulanan testler sonucunda elde edilen sonuçlar Tablo 4' de gösterilmiştir.

Tablo 4. Öğretmenlerin Dijital Vatandaşlığa Yönelik Alg1 Düzeylerinin Branş Değişkenine Göre Analiz Sonuçları

\begin{tabular}{|c|c|c|c|c|c|c|c|c|}
\hline Boyut & & Branş & $\mathbf{N}$ & $\square$ & Ss & Sd & $\mathbf{F}$ & $\mathbf{p}$ \\
\hline \multirow{3}{*}{\multicolumn{2}{|c|}{ Dijital iletişim }} & Sinif & 133 & 1.99 & .76 & 2 & & \\
\hline & & Okul öncesi & 30 & 1.64 & .49 & 204 & 3.30 & .39 \\
\hline & & Diğer branş & 52 & 2.08 & .80 & & & \\
\hline Dijital hak & ve & Sinif & 133 & 2.64 & .48 & 2 & & \\
\hline \multirow{2}{*}{\multicolumn{2}{|c|}{ sorumluluklar }} & Okul öncesi & 30 & 2.72 & .62 & 204 & .39 & .67 \\
\hline & & Diğer branş & 52 & 2.71 & .62 & & & \\
\hline \multirow{3}{*}{\multicolumn{2}{|c|}{ Eleştirel düşünme }} & Sinif & 133 & 2.56 & .59 & 2 & & \\
\hline & & Okul öncesi & 30 & 2.48 & .59 & 190 & .83 & .43 \\
\hline & & Diğer branş & 52 & 2.41 & .73 & & & \\
\hline \multirow{3}{*}{\multicolumn{2}{|c|}{ Dijital katılım }} & Sinif & 133 & 3.44 & .90 & 2 & & \\
\hline & & Okul öncesi & 30 & 3.55 & .71 & 172 & 2.67 & .07 \\
\hline & & Diğer branş & 52 & 3.14 & .83 & & & \\
\hline \multirow{3}{*}{\multicolumn{2}{|c|}{ Dijital güvenlik }} & Sinif & 133 & 2.40 & .68 & 2 & & \\
\hline & & Okul öncesi & 30 & 2.07 & .66 & 180 & 4.37 & .12 \\
\hline & & Diğer branş & 52 & 2.10 & .73 & & & \\
\hline \multirow{3}{*}{\multicolumn{2}{|c|}{ Dijital beceriler }} & Sinif & 133 & 3.96 & .83 & 2 & & \\
\hline & & Okul öncesi & 30 & 3.45 & .82 & 180 & 6.16 & .12 \\
\hline & & Diğer branş & 52 & 2.29 & .54 & & & \\
\hline \multirow{2}{*}{\multicolumn{2}{|c|}{ Etik }} & Sinif & 133 & 2.67 & .50 & 2 & & \\
\hline & & Okul öncesi & 30 & 2.57 & .37 & 176 & .56 & .56 \\
\hline
\end{tabular}




\begin{tabular}{lccccccc} 
& Diğer branş & 52 & 2.61 & .51 & & & \\
Dijital ticaret & Sınıf & 133 & 4.04 & .51 & 2 & & \\
& Okul öncesi & 30 & 3.75 & .95 & 180 & 3.43 & .13 \\
& Diğer branş & 52 & 3.75 & 1.01 & & & \\
Toplam & & & & & & \\
& Sinıf & 133 & 3.14 & .28 & 2 & & .12 \\
& Okul öncesi & 30 & 2.98 & .32 & 144 & 2.15 & .43 \\
\hline
\end{tabular}

Tablo 4' deki tek yönlü anova sonuçlarına göre, öğretmenlerin dijital vatandaşlığa yönelik algılarının ölçeğin bütününü dikkate alındığında anlamlı fark göstermediği saptanmıştır $\left[\mathrm{F}_{(2-204)}=2.15 ; \mathrm{p}>.05\right]$. Bununla birlikte dijital hak ve sorumluluk $\left[\mathrm{F}_{(2-204)}=.39 ; \mathrm{p}>.05\right]$, eleştirel düşünme $\left[\mathrm{F}_{(2-190)}=.83 \mathrm{p}>.05\right]$, dijital katılım $\left[\mathrm{F}_{(2-172)}=2.67 \mathrm{p}>.05\right]$, etik $\left[\mathrm{F}_{(2-176)}=\right.$ $.56 ; p>.05]$, dijital ticaret $\left[\mathrm{F}_{(2-180)}=3.43 \mathrm{p}>.05\right]$, dijital iletişim $\left[\mathrm{F}_{(2-204)}=3.30 ; \mathrm{p}<.05\right]$, dijital güvenlik $\left[\mathrm{F}_{(2-180)}=4.37 \mathrm{p}<.05\right]$ ve dijital beceriler $\left[\mathrm{F}_{(2-180)}=6.16 ; \mathrm{p}<.05\right]$ boyutlarında da öğretmenlerin algılarının branş değişkeni bakımından anlamlı fark göstermediği tespit edilmiştir.

Öğretmenlerin dijital vatandaşlı̆̆a yönelik algı düzeyini oluşturan alt boyutlarının kıdem değişkenine göre farklılaşıp farklılaşmadığını belirlemek amacıyla bağımsız gruplar t testi uygulanmış ve sonuçlar Tablo 5'de gösterilmiştir.

Tablo 5. Öğretmenlerin Dijital Vatandaşlığa Yönelik Algılarının Kıdem Yılı Değişkenine Göre Analiz Sonuçları

\begin{tabular}{|c|c|c|c|c|c|c|c|}
\hline Boyut & Kıdem Yılı & $\mathbf{N}$ & $\overline{\bar{X}}$ & Ss & df & $\mathbf{t}$ & $\mathbf{p}$ \\
\hline \multirow[t]{2}{*}{ Dijital İletişim } & $1-5$ y1l arası & 160 & 1.85 & .64 & \multirow[t]{2}{*}{205} & \multirow[t]{2}{*}{$-3,78$} & \multirow[t]{2}{*}{.00} \\
\hline & 6 yil ve üzeri & 55 & 2.30 & .94 & & & \\
\hline Dijital Hak ve & 1-5 y1l arası & 160 & 3.83 & .53 & \multirow[t]{2}{*}{205} & \multirow[t]{2}{*}{$-2,36$} & \multirow[t]{2}{*}{.01} \\
\hline Sorumluluklar & 6 yil ve üzeri & 55 & 3.62 & .52 & & & \\
\hline Eleştirel & $1-5$ y1l arası & 160 & 3.49 & .62 & 205 & -.87 & .00 \\
\hline Düşünme & 6 yil ve üzeri & 55 & 2.58 & .64 & & & \\
\hline \multirow[t]{2}{*}{ Dijital Katılım } & 1-5 y1l arası & 160 & 3.46 & .83 & \multirow[t]{2}{*}{205} & \multirow[t]{2}{*}{2,04} & \multirow[t]{2}{*}{.04} \\
\hline & 6 yil ve üzeri & 55 & 3.17 & .93 & & & \\
\hline \multirow[t]{2}{*}{ Dijital Güvenlik } & $1-5$ y1l arası & 160 & 3.27 & .64 & \multirow[t]{2}{*}{205} & \multirow[t]{2}{*}{-.22} & \multirow[t]{2}{*}{.00} \\
\hline & 6 yil ve üzeri & 55 & 2.29 & .85 & & & \\
\hline \multirow[t]{2}{*}{ Dijital Beceriler } & $1-5$ y1l arası & 160 & 3.96 & .79 & \multirow[t]{2}{*}{205} & \multirow[t]{2}{*}{1,52} & \multirow[t]{2}{*}{.00} \\
\hline & 6 yil ve üzeri & 55 & 3.56 & .80 & & & \\
\hline \multirow[t]{2}{*}{ Etik } & $1-5$ y1l arası & 160 & 2. 69 & .45 & \multirow[t]{2}{*}{205} & \multirow[t]{2}{*}{2,49} & \multirow[t]{2}{*}{.01} \\
\hline & 6 yil ve üzeri & 55 & 2.49 & .54 & & & \\
\hline
\end{tabular}


doi:10.33711/yyuefd.693832

Dijital Ticaret

1-5 yıl arası

6 yıl ve üzeri

Toplam

\section{Araştırma Makalesi}

160

55

160

55
4. 01

3.70

4. 11

3.11
ISSN: 1305-2020

205

2, 43

.01

.89

.29

.42
$205 \quad-.09$

.00

Tablo 5 de görüldüğü gibi öğretmenlerin dijital vatandaşlığa ilişkin algıları ölçeğin bütünü dikkate alındığında kıdem yılı değişkeni açısından 1-5 yıl kıdem yılına sahip öğretmenler ile 6 yıl ve üzeri kıdeme sahip öğretmenler arasında 1-5 yıl kıdeme sahip öğretmenler lehine anlamlı bir fark göstermektedir $\left(\mathrm{t}_{(205)}=-.09 \mathrm{p}<.05\right)$. Benzer şekilde, 15 yıllık mesleki kıdeme sahip öğretmenler ile 6 yıl ve üzeri yıllık mesleki kıdeme sahip öğretmenler arasında ölçeğin dijital hak ve sorumluluklar $\left(\mathrm{t}_{(205)}=-2.36, \mathrm{p}<.05\right)$ ile eleştirel düşünme $\left(\mathrm{t}_{(205)}=-.87, \mathrm{p}>.05\right)$ boyutlarında 1-5 yıllık mesleki kıdeme sahip öğretmenler lehine anlamlı farklılıklar belirlenmiştir. Bunun yanı sıra, dijital katılım $\left(\mathrm{t}_{(205)}=2.04, \mathrm{p}>.05\right)$, dijital güvenlik $\left(\mathrm{t}_{(205)}=-.22, \mathrm{p}<.05\right)$, dijital beceriler $\left(\mathrm{t}_{(205)}=1.52, \mathrm{p}<.05\right)$, etik $\left(\mathrm{t}_{(205)}=2.49, \mathrm{p}<\right.$ $.05)$ ve dijital ticaret $\left(\mathrm{t}_{(205)}=2.43, \mathrm{p}<.05\right)$ boyutlarında da $1-5$ y1ll1k mesleki k1deme sahip öğretmenler ile 6 yıl ve üzeri mesleki kıdeme sahip öğretmenler arasında 1-5 y1llık mesleki kıdeme sahip öğretmenler lehine anlamlı farklılıklar gözlemlenmiştir.

\section{Tartışma ve Sonuç}

Araştırmada öğretmenlerin dijital vatandaşlığa yönelik algılarının orta düzeyde olduğu belirlenmiştir. Bu durumu Tatlı (2018) tarafından farklı branşlarda görev yapan öğretmenlerle gerçekleştirilen araştırma bulguları da desteklemektedir. Bununla birlikte farklı anabilim dallarında öğrenimlerini sürdüren öğretmen adaylarıyla gerçekleştirilen araştırma bulgularında da öğretmen adaylarının dijital vatandaşlığa yönelik algılarının yüksek düzeyde çıktığı belirlenmiştir (Bakır, 2016; Kocadağ, 2016; Sakallı, 2015). Bu araştırmada öğretmenlerin dijital vatandaşlığa yönelik algılarının bazı boyutlar açısından olumsuz olduğu söylenebilir. Öğretmenlerin olumsuz algıya sahip olduğu boyutların dijital güvenlik ve dijital iletişim boyutları olduğu tespit edilmiştir. Bilgi ve iletişimin hızlı şekilde değiştiği günümüzde dijital ortama uyum sağlamanın zorlaştığı araştırmacılar tarafından vurgulanmaktadır (Kadll, Kumba \& Kanamad, 2010; Oyedemi, 2012; Symantec, 2010). Bu bağlamda öğretmenlerin elektronik ortamda ya da sanal ortamda bilgi paylaşımlarının zayıf olması da bu durumun nedeni olabilir. $\mathrm{Bu}$ durumun bir başka nedeni ise öğretmenlerin kişisel ya da ortak erişime sahip araçları kullanırken ne gibi güvenlik önlemlerini almaları gerektiğini bilmemelerinden (Ribble ve 
Bailey 2007) kaynaklanabilir. Benzer şekilde Kilci (2019) tarafından sosyal bilgiler öğretmenleriyle gerçekleştirilen araştırmada da öğretmenlerin dijital vatandaşlık konusunda zayıf kaldıkları tespit edilmiştir. Öğretmenlerin dijital vatandaşlık konusunda yetkin olabilmeleri lisans öğretimi gördükleri öğretim kademelerinde bu konuda kuramsal ve uygulamalı eğitim almaları ile mümkün olabilir (Lindsey, 2015). Hem öğretmenlerde hem de eğitim kurumlarında görev yapan yöneticilerde dijital vatandaşlığa yönelik farkındalığın geliştirilmesi gerekir (Hollandsworth, Donovan \& Welch, 2017). Bu çerçevede öğretmen yetiştirmeyi amaçlayan kurumların lisans programlarında dijital vatandaşlıkla ilgili konulara yer vermesi gerekir (Fluck \& Dowden, 2013). Öğretmenlerin hizmet içi eğitimlerle dijital vatandaşlık konusundaki farkındalıklarını artırıcı becerilerle donanmaları sağlanabilir. Bununla birlikte öğretmenlerin dijital vatandaşlık algısını geliştirici seminerler ve atölye çalışmaları düzenlenebilir. Bu seminerler ve atölye çalışmaları aracılığıyla öğretmenlerin dijital hak ve sorumluluklarının bilincinde olmaları, dijital güvenlik konusunda beceri edinmeleri sağlanabilir. Bununla birlikte bu çalışmalar sayesinde öğretmenlerin dijital iletişim ve etik konularındaki farkındalıkları artırılabilir.

Araştırmada dikkat çekici bir diğer bulgu ise erkek öğretmenlerin dijital vatandaşlığa yönelik algılarının kadın öğretmenlere göre anlamlı farklılık yaratmasıdır. Başka bir ifadeyle cinsiyet öğretmenlerin dijital algılarını belirlemede etkili bir değişkendir. Buna karşın Tatlı (2018) tarafindan gerçekleştirilen araştırmada cinsiyet öğretmenlerin dijital vatandaşlığa yönelik algılarını belirlemede etkili bir değişken olarak ortaya çıkmamıştır. Öğretmen adaylarıyla ve öğrencilerle gerçekleştirilen çalışmalarda ise cinsiyetin dijital vatandaşlık algısını belirlemede etkili bir değişken olduğu ve bu farkın erkek öğretmen adayları ve öğrenciler lehine olduğunu ortaya çıkaran araştırmalara rastlanmıştır (Bakır, 2016; Çepni, Oğuz \& Kılcan 2014, İşman \& Çukurbaş1 2014, Kocadăg, 2012). Bu araştırmada dijital vatandaşlığın "Dijital iletişim”, ve "Dijital ticaret” boyutlarında ise erkek öğretmenlere göre kadın öğretmenlerin algılarının daha yüksek düzeyde olduğu saptanmıştır. Dijital çağ olarak ifade edilen küresel dünyada birçok ürünün internet ağları aracılığıyla alım ve satımının gerçekleştirildiği dikkate alındığında (Villano, 2008) kadın öğretmenlerin dijital ortamlardaki alışveriş sitelerini erkek öğretmenlere göre daha fazla izledikleri, buralardan daha fazla alışveriş yaptıkları düşünülebilir. Bunun yanı sıra kadın öğretmenlerin sosyal ilişkileri geliştirmede dijital ortamı erkek öğretmenlere göre daha fazla kullandıkları ve bu alanlarda daha fazla bilgi paylaşımında bulundukları söylenebilir. Ayrıca kadın öğretmenlerin dijital ortamlarda erkek 
öğretmenlere göre daha fazla sosyal ilişki yürüttükleri düşünülebilir. Bu araştırmada dikkat çekici diğer bir nokta ise erkek öğretmenlerin dijital hak ve sorumluluk bilincinin kadın öğretmenlere göre yüksek düzeyde olmasıdır. Bu noktadan hareketle erkek öğretmenlerin dijital ortamlarda sahip oldukları hakların ve üstlendikleri sorumlulukların kadın öğretmenlere daha fazla farkında olduğu ifade edilebilir.

Ölçeğin tamamı incelendiğinde branş değişkeninin öğretmenlerin dijital algılarını belirlemede etkili bir değişken olmadığı saptanmıştır. Başka bir ifadeyle farklı branşlarda görev yapan öğretmenlerin dijital vatandaşlık algılarının birbirine yakın olduğu söylenebilir. Dijital vatandaşlığın temel göstergelerinden biri de dijital bilgilere etkin şekilde ulaşıp bunları kişisel ve toplumsal açıdan kullanabilme becerisidir (Farmer, 2010). Bu çerçevede branş farklılığına rağmen öğretmen adaylarının bu becerileri kullanma düzeylerinin biri birine yakın olduğu söylenebilir. Buna ek olarak farklı branşlarda görev yapan öğretmenlerin bilgi iletişim araçlarını kullanmaya yönelik davranış eğilimlerinin benzerlik taşıdığı düşünülebilir. Ayrıca farklı branşlardaki öğretmenlerin bilgi iletişim teknolojilerini kullanmaya yönelik benzer davranış biçimleri sergiledikleri söylenebilir.

Mesleki kıdem değişkeninin öğretmenlerin dijital vatandaşlığa yönelik algılarını belirleyen etkili bir değişken olduğu belirlenmiştir. 1-5 yıllık mesleki kıdeme sahip öğretmenlerin dijital vatandaşlığa yönelik algılarının ölçeğin tamamında ve boyutlarında 6 ve üzeri yıllık kıdeme sahip öğretmenlere göre anlamlı fark gösterdiği saptanmıştır. 1-5 yıllık kıdeme sahip ögretmenlerin bilgi iletişim teknolojilerinde dolayısıyla dijital ortamda gerçekleşen değişimleri yakından izlemeleri bu bulgunun ortaya çıkmasında belirleyici olabilir. Ayrıca, küreselleşme kavramıyla toplumsal ve kültürel değişimin yaşandığı günümüzde (Giddens, 2008; Thio,2005) 1-5 yıllık mesleki kıdeme sahip öğretmenlerin bilgi iletişim teknolojilerini öğrenme ve bunları eğitim sürecine dahil etme yeteneklerinin, toplumsal yaşama dijital ortamlarda etkin katılımlarının (Ribble, Bailey \& Ross, 2004) 6 ve üzeri kıdeme sahip öğretmenlere göre daha yüksek düzeyde olması da bu durumun nedenlerinden biri olabilir.

\section{Makalenin Bilimdeki Konumu}

Eğitim Bilimleri Bölümü /Eğitim Programları ve Öğretim

\section{Makalenin Bilimdeki Özgünlüğü}

İlgili alan yazın incelendiğinde dijital vatandaşlıkla ilgili araştırmaların büyük oranda öğretmen adaylarıyla gerçekleştirildiği tespit edilmiştir. Buna karşın öğretmenlerle 
gerçekleştirilen araştırmaların sınırlı olduğu saptanmıştır. Bilgi ve iletişim teknolojilerinin hızla değiştiği ve geliştiği çağımızda dijital okuryazarlık önemli bir unsur haline gelmektedir. Eğitim kurumlarının en önemli yapıtaşı olan ve genç nesilleri çağın ihtiyaçlarına uygun şekilde yetiştirecek öğretmenlerin dijital okuryazarlıklarının incelenmesinin alana katkıda bulunacağı düşünülmektedir.

\section{Öneriler}

Araştırmanın nitel ve karma araştırma yöntemleriyle gerçekleştirilmesi öğretmenlerin dijital vatandaşlığa yönelik algılarını belirlemede etkili olabilir. Bununla birlikte öğretmenlerle gerçekleştirilecek nicel araştırmaların farklı örneklem gruplarında gerçekleştirilmesi öğretmenlerin dijital vatandaşlığa ilişkin algılarına yönelik genel bir çerçeve sunabilir. Öğretmenlerin dijital vatandaşlığa yönelik algılarının bazı boyutlarda düşük düzeyde olduğu saptanmıştır. $\mathrm{Bu}$ boyutların düşük düzeyde çıkma nedenleri farklı araştırma yöntemleri kullanılarak incelenebilir. Ayrıca 5-10 y1llık mesleki deneyime sahip öğretmenlerin dijital vatandaşlığa yönelik algılarını olumlu yönde destekleyecek çeşitli hizmet içi eğitimler verilebilir.

\section{Kaynaklar}

Aladağ, S. ve Çiftci, S. (2017). An investigation of the relationship between digital citizenship levels of preservice primary school teachers and their democratic values. European Journal of Education Studies, 3(6), 171- 184.

Aslan, S. (2016). Illköğretim sosyal bilgiler öğretmen adaylarını dijital vatandaşlık davranışlarını bazı değişkenler açısından incelenmesi (fırat, dicle, siirt, adıyaman üniversiteleri örneği) . (Yayımlanmamış yüksek lisans tezi). T.C. Fırat Üniversitesi Eğitim Bilimleri Enstitüsü Sosyal Bilgiler Eğitimi Ana Bilim Dalı, Elazığ.

Aydemir, M . (2019). Yenilenen sosyal bilgiler dersi öğretim programının dijital vatandaşlık ve alt boyutları açısından incelenmesi. Uluslararası Güncel Ĕgitim Araştırmaları Dergisi, 4 (2) , 15-38.

Bakır, E.(2016). Sınıföğretmeni adaylarının dijital vatandaşlık seviyelerinin dijital vatandaşlık alt boyutlarına göre incelenmesi. (Yayımlanmamış yüksek lisans tezi). Karadeniz Teknik Üniversitesi Eğitim Bilimleri Enstitüsü Bilgisayar ve Öğretim Teknolojileri Eğitim Anabilim Dalı, Trabzon. 
Banks, J. A. (2004). Teaching for social justice, diversity, and citizenship in a global world. The Educational Forum, 68 (4), 296-305.

Bardakçı, S., Akyüz, H.İ., Samsa-Yetik, S. ve Keser, H. (2014). Öğretmen adaylarının dijital vatandaşlık eğilimleri üzerine sosyokültürel bir inceleme. 8th International Computer \& Instructional Technologies Symposium (ICITS), Trakya University, Edirne.

Barth, J. L. ve Demirtaş, A. (1997). İlköğretim sosyal bilgiler öğretimi. Ankara: Yök/ Dünya bankası milli eğitimi geliştirme projesi hizmet öncesi öğretmen eğitimi. Educational Forum, 68, 289-298.

Baş, T. (2003). Anket, nasıl yapılır, uygulanır, değerlendirilir? Ankara: Seçkin yayıncılık.

Büyüköztürk, Ş., Çakmak, E. K., Akgün, Ö.E., Karadeniz, Ş. ve Demirel, F. (2008). Bilimsel Araştırma Yöntemleri. Ankara:PegemA Yayıncılık.

Kaya, B. \& Kaya, A. . (2012). Teknoloji çağında öğretmen adaylarının küresel vatandaşlık alg1ları. Sakarya University Journal of Education, 2 (3), 81-95.

Ceylan, Ş. (2014). Okul öncesi öğretmenlerinin dünya vatandaşlı̆̆ı eğitimi ile ilgili görüşleri. Kuramsal Eğitimbilim Dergisi, 7(1), 78-93.

Çubukcu, A. \& Bayzan, Ş. (2013). Türkiye'de dijital vatandaşlık algısı ve bu algıyı internetin bilinçli, güvenli ve etkin kullanımı ile artırma yöntemleri. Middle Eastern \& African Journal of Educational Research, 5, 148-174.

Çepni O., Oğuz S. ve Kılcan B. (2014). İlköğretim Öğrencilerinin Dijital Vatandaşlığa Yönelik Görüşleri. Türkiye Sosyal Araştırmalar Dergisi. 18 (3), 251-266.

Dere, İ., Yavuzay, M . (2019). Sosyal bilgiler öğretmen adaylarının dijital vatandaşlık göstergelerinin incelenmesi. MANAS Sosyal Araştırmalar Dergisi, 8 (3) , 2400-2414

Doğan, İ. (2005). Vatandaşlık, demokrasi ve insan hakları. Ankara: Pegem Yayıncılık

Engin, G., ve Sarsar, F. (2015). Investigation of primary school teacher candidates ${ }^{e e}$ global citizenship levels. International Journal of Human Sciences, 12(1), 150-161

Farmer, L. (2010) 21. Century Standarts for Information Literacy. Leadership, 39 (4), 20-22.

Fluck, A., \& Dowden, T. (2013). On the Cusp of Change: Examining Preservice Teachers' Beliefs about ICT and Envisioning the Digital Classroom of the Future. Journal of Computer Assisted Learning, 29 (1), 43-52. doi: 10.1111/j.1365-2729.2011.00464.x

George, D., \& Mallery, M. (2010). SPSS for Windows Step by Step: A Simple Guide and Reference, 17.0 update (10a ed.) Boston: Pearson. 
Gibson, K.L, Rimmington G.M. \& Landwehr-Brown M. (2008). Developing global awareness and responsible world citizenship with global learning, ISSN: 0278-3193 print / 1940$865 \mathrm{X}$ online.

Giddens, A. (2008) The third way, the renewal of social democracy . Cambridge: Polity.

Görmez, E. (2017). İlkokul sosyal bilgiler programının dijital vatandaşlık ve alt boyutları açısından yeterliliği. International Journal of Social Science 2,(60), 1-15.

İşman, A. \& Güngören, Ö. C. (2014). Digital citizenship. The Turkish Online Journal of Educational Technology, 13(1), 73-77.

Hollandsworth, R., Donovan, J., Welch, M.: Digital citizenship: you can’t go home again. TechTrends, 61, 524-530

Kadll, J. H., Kumba B.D., \& Kanamad S.J. (2010). Students perspectives·on internet usage: a case study. Information Studies, 16 (2), 103-112.

Kan, Ç. (2009). Sosyal bilgiler eğitiminde küresel vatandaşlık. Pamukkale Üniversitesi Ĕ̆itim Fakültesi Dergisi, 26(26), 25-30.

Karaduman, H. (2011). 6. sınıf sosyal bilgiler dersinde dijital vatandaşlı̆̆a dayalı etkinliklerin ögrencilerin dijital ortamdaki tutumlarına etkisi ve öğrenme ögretme sürecine yansımaları. (Yayımlanmamış Doktora Tezi), Marmara Üniversitesi Eğitim Bilimleri Enstitüsü, İstanbul.

Karasar, N. (2000). Bilimsel Araştırma Yöntemi. Ankara: Nobel Yayınevi.

Kaya, A. ve Kaya, B. (2014). Öğretmen adaylarının dijital vatandaşlık algısı. International Journal of Human Sciences, 11(2), 346-361.

Kilci, Z. (2019). Sosyal bilgiler ögretmenlerinin dijital vatandaşlı̆̆a yönelik görüşleri ve uygulamaları, (Yayımlanmamış yüksek lisans tezi), Sosyal Bilgiler Eğitimi Programı Türkçe ve Sosyal Bilimler Eğitimi Anabilim Dalı, Eskişehir, 2019.

Kocadağ, T. (2012). Öğretmen adaylarının dijital vatandaşlık düzeylerinin belirlenmesi. (Yayımlanmamış yüksek lisans tezi), Karadeniz Teknik Üniversitesi Eğitim Bilimleri Enstitüsü Bilgisayar ve Öğretim Teknolojileri Eğitimi Anabilim Dalı, Trabzon.

Kozan, M. (2018). Öğretmen adaylarının dijital okuryazarlık düzeyleri ve siber zorbalığa ilişkin duyarlılıklarının incelenmesi. (Yayımlanmamış yüksek lisans tezi). T.C. Fırat Üniversitesi Eğitim Bilimleri Enstitüsü Bilgisayar ve Öğretim Teknolojileri Eğitimi Anabilim Dalı, Elazı̆̆. 
Kuş, Z., Güneş, E., Başarmak, U., \& Yakar, H. (2017). Development of a Digital Citizenship Scale for Youth: A validity and reliability study. Journal of Computer and Education Research , 5 (10) , 298-316.

Lim, M. (2008). Digital media and Malaysia's electoral reform movement. citizenship and democratization in southeast in asi. Boston: Brill.

Lindsey, L. (2015). Preparing teacher candidates for 21st century classrooms: A Study of digital citizenship. Doctoral dissertation, Arizona State University, Arizona

Merey, Z., Karatekin, K. \& Kuş, Z. (2012). İlköğretimde vatandaşlık eğitimi: karşılaştırmalı kuramsal bir çalışma. Gazi Ĕgitim Fakültesi Dergisi, 32(3), 795-821.

Mossberger, K., Tolbert, C., \& S. McNeal, R. (2007). Digital Citizenship: The internet, society, and participation. London, England: The MIT Press.

Ortloff, D. H. (2011). Moving the borders: multiculturalism and global citizenship in the German social studies classroom, Educational Research, 53 (2), 137-149.

Oxfam (2006). Education for global citizenship: A guide for schools. http://www.oxfam.org.uk/coolplanet/teachers/globciti/downloads/gcguide06.pd f. Erişim Tarihi: 6.10.2019.

Oyedemi, T. D. (2012). The Partially Digital: Internet, Citizenship, Social Inequalities, And Digital Citizenship. In South Africa. Unpublished doctoral dissertation, Obafem1 Awolowo Unıversity, Nigeria.

Sakallı, H. (2015). Sınıf öğretmeni adaylarının dijital vatandaşlık düzeyleri ile siber zorbalık eğilimleri arasındaki ilişkinin incelenmesi, (Yayımlanmamış yüksek lisans tezi). T.C. Adnan Menderes Üniversitesi Sosyal Bilimler Enstitüsü İlköğretim Anabilim Dalı Sınıf Öğretmenliği Programı, Aydın.

Ribble, M. \& Bailey, G. (2007). Digital citizenship in schools. Washington, DC: ISTE.

Ribble, M., Bailey, G., \& Ross, T. (2004). Digital citizenship: Addressing appropriate technology behavior. Learning and Leading with Technology, 32, 6-9.

Schattle, H. (2008). Education for global citizenship: Illustrations of ideological pluralism and adaptation, Journal of Political Ideologies, 13 (1),73-94.

Som Vural, S , Kurt, A . (2018). Üniversite Öğrencilerinin Bakış Açısıyla Dijital Vatandaşlık Göstergelerinin İncelenmesi. Eğitim Teknolojisi Kuram ve Uygulama, 8 (1), 60-80.

Stavenhagen, R. (2008). Building interculturel citizenship through education: A human rights approach. European Journal of Education, 43(2), 161-179. 
Symantec. (2010). The Norton online family report. http://proquest.umi.com/pqdweb ?did=2058416671\&sid=1\&Fmt=3\&clientId=41947\&RQT=309\&VNam e=PQD. Erişim Tarihi: 08.09.2019.

Takkac, M. \& Akdemir,A. S.(2012). Training future members of the world with an understanding of global citizenship. Procedia - Social And Behavioral Sciences 47, 881 -885 .

Tatlı, A. (2018). Öğretmenlerin dijital vatandaşlık düzeylerinin bilgi okuryazarlı̆̆ ve bilgisayar kullanım özyeterlikleri bağlamında değerlendirilmesi, (Yayımlanmamış yüksek lisans tezi), T.C. Necmettin Erbakan Üniversitesi Eğitim Bilimleri Enstitüsü Bilgisayar Ve Öğretim Teknolojileri Eğitim Anabilim Dalı Bilgisayar ve Öğretim Teknolojileri Eğitimi Bilim Dalı, Konya.

Tezcan, M. (2004). Postmodern ve küresel toplumda ĕgitim. Ankara: Anı Yayıncılık.

Thio, A. (2005). Sociolog: A Brief Introduction. Boston: Pearson.

Turan S . ve Karasu A. E. (2018). 2018 sosyal bilgiler öğretim programı'nın dijital vatandaşlık bağlamında incelenmesi. Eğitim ve Yeni Yaklaşımlar Dergisi, 1(1), 28-38.

Villano, M. (2008). Text unto other As You Would Have Them Text Unto You. The Journal, 35(9) 47-51.

Vural, S. ve Kurt, A. (2018). Üniversite öğrencilerinin bakış açısıyla dijital vatandaşlık göstergelerinin incelenmesi. Educational Technology Theory and Practice, 8 (1), 60-80.

Zahabioun, S., Yousefy, A., Yarmohammadian, M. H. \& Keshtiaray, N. (2013). Global citizenship education and 1ts 1mplications for curriculum goals at the age of globalization, International Education Studies, 6 (1), 195-206.

\section{Summary}

\section{Introduction}

Information communication technologies have contributed to the formation of a common world order and universal culture. Thanks to the digital world, individuals can be aware of the events taking place at the other end of the world and have the opportunity to express their feelings and thoughts against the events that develop on the same platform. The events taking place in digital environments make the citizens feel that they have responsibilities not only to the society they live in but to the whole universe. 
In this context, it is expected to raise citizens who are responsible for the universe they live in who have universal awareness and sensitivity. The citizen with these criteria is called “digital citizen (Farmer, 2010; Kan, 2009).

The main purpose of education is to raise productive individuals who benefit the country and the world. Citizenship training is mainly given within the scope of targeted social studies course. With the globalization of the world, individuals are not limited to the borders of a country. On the contrary, a universal culture emerges and individuals can meet in a common ground with globalization. In the light of the literature findings 'digital citizenship' trainings should be conducted order to raise more conscious and responsible individuals and it should be aimed to raise citizens who are more sensitive to the events taking place in the world (Stavenhagen, 2008).

The universal problems (cultural, socioeconomic, political and environmental ones) that concern the whole world have led teachers to educate their students to be sensitive to these problems, to respect different cultures, to empathize, and to show courage to solve universal problems and adapt to the modern world. Educators, program developers who are experts in their fields and researchers have a great responsibility to train individuals who are aware of the requirements of the digital world and who can fulfill their responsibilities. Ensuring equality in education in the modern world is only possible by having sufficient skills and skills to compete with other individuals in the world at a basic level. For this purpose, students should be provided with the necessary skills such as education, professional capacity, at least one foreign language outside their mother tongue and being intellectual to ensure that they are not ordinary individuals. Digital citizenship education is crucial in providing these skills (Lim, 2008; Takkac and Akdemir, 2012).

\section{Aim of the Study}

The aim of this study was to measure teachers' perception of digital citizenship. In this context, the answer to the following research questions is sought.

1. What is the level of prospective teachers' perception of 'digital citizenship'?

2. Do prospective teachers' 'digital citizenship' perceptions differ significantly by the gender?

3. Do 'digital citizenship' perceptions differ significantly by the field?

4. Do 'digital citizenship' perceptions differ significantly according to their years of seniority?

Method 


\section{Research Model}

In this research, cross-sectional survey model was used. The cross-sectional research model is a research model that aims to determine whether independent variables are applied and measured once and whether they differ according to other variables (Fraenkel \& Wallen, 2006). In the current study, this research model was selected since the related data was collected from teachers at once.

\section{Population and Sampling}

The population of study consists of 400 teachers working with different profession Şırnak city center in 2018-2019 academic year. The sample of the study consists of 215 randomly selected teachers who were determined by random (impartial) assignment. The sample size required for the study was calculated using the formula proposed by Bas (2003). It is recommended to work with at least 195 teachers according to this formula. In this context, the sample of the study is sufficient to meet the universe.

\section{Data Collection Tool}

'Digital Citizenship' scale developed by Kuş et al. (2017) was used to determine individuals' perceptions of digital citizenship. The scale consist of 48 item with eight dimensions. It is a five-point Likert-type scale and consists of eight factors and 49 items. The reability of this instrument's Cronbach Alpha was found to be range of between 0.73 and 0 . 82.

\section{Discussion and Result}

In this study, it was determined that teachers' perceptions about digital citizenship were moderate The findings of the study support the results of the Tatl1 (2018) who conducted a research with teachers working in different fields. In addition, the findings of the research conducted on prospective teachers who studying in different departments revealed that pre service teacher's perception of digital citizenship was high (Bakır, 2016; Sakallı and Çiftçi, 2016; Kocadağ, 2016).

Another noteworthy finding in the study is that there is a statistically significant difference between the male and female teachers' perception of digital citizenship in favor of men. In other words, gender is an effective variable in determining teachers' digital perceptions. When the whole scale was examined, it was found that the professional field variable was not an effective variable in determining the teachers' digital perceptions. In other words, it can be said that the perception of digital citizenship of teachers working in different fields have similar. Perception of digital citizenship. It has been determined that the professional years of seniority 
variable was found to be effective variable in determining teachers' perception of digital citizenship. It was found that the perception of digital citizenship of teachers with 1-5 years of seniority showed a significant difference compared to teachers with 5-10 years of seniority.The capacity of teachers with 1-5 years of seniority to closely monitor the changes in information communication technologies and therefore it can be decisive for the finding in the digital environment

\section{Recommendations}

Conducting research with qualitative and mixed research methods may be effective in determining teachers' perceptions of digital citizenship. However, quantitative research on teachers in different sample groups may provide a general framework for teachers' perceptions of digital citizenship. Teachers' perception of digital citizenship was found to be low in some dimensions. The reasons for the low level of these dimensions can be examined by using different research methods. In addition, various in-service trainings can be provided to support perceptions of digital citizenship of teachers with 5-10 years of professional experience

\section{EKLER}

Ek 1: Dijital Vatandaşlık Ölçeğinin Alt Boyutlarına İlişkin Örnek Maddeler

\begin{tabular}{ll}
\hline Alt Boyut & Örnek Madde \\
\hline Dijital İletişim & Dijital ortamda tanımadı̆̆ım kişilerle iletişim kurarım. \\
Dijital Hak ve Sorumluluk & Dijital ortamlarda sahip olduğum hakları tam olarak \\
& bilmiyorum \\
Eleştirel Düşünme & Dijital ortamda okuduğum bilgiler, günlük hayattaki \\
& düşüncelerimi ve kararlarımı etkiler. \\
Dijital Katılım & Dijital ortamlarda, resmi kurumlardan bilgi edinme \\
& hakkımı kullanırım. \\
Dijital Güvenlik & Dijital ortamlarda genellikle aynı şifreleri kullanırım \\
Dijital Beceriler & İhtiyacım olan bilgilere İnternet üzerinden rahatlıkla \\
& ulaşabilirim. \\
Etik & Telif hakkını ihlal eden durumları bilirim. \\
Dijital Ticaret & Alışveriş yaptığım web sitelerinin kurumsal ve \\
& güvenilir olmasına dikkat ederim. \\
\hline
\end{tabular}

